\title{
EXPLAINING THE ADOPTION OF SOCIAL NETWORK SITES FOR SHARING \\ USER-GENERATED CONTENT: A REVISION OF THE UTAUT2
}

\begin{abstract}
Despite the outstanding growth of social network sites in recent years, more research is needed to better understand how users' intentions to share their experiences with products and brands are formed through these applications. With this in mind, this study takes the Unified Theory of Acceptance and Use of Technology 2 (UTAUT2) as a reference and develops an extended model by considering the substitution of "price value" with "privacy concerns", since social network sites are free applications, with no economic cost to users but with potential problems of self-disclosure. Our model also includes the interrelations between the explanatory variables postulated in the UTAUT2, an issue that is not considered in its original formulation. This approach is empirically tested through a quantitative study in the tourism industry, where social network sites have significant influence. The results from a sample of 537 tourists show that there are three main drivers of users' intentions to use social network sites to publish content about their experiences: performance expectancy, hedonic motivation, and habit. Additionally, our results support the existence of interrelations between the explanatory variables. Finally, three of the factors studied (i.e., facilitating conditions, social influence, and privacy concerns) do not have any influence on the intention to use social network sites to share content.
\end{abstract}

\section{Keywords}

Social network sites (SNS), user-generated content, UTAUT2, behavioral intentions, privacy concerns 


\section{INTRODUCTION}

Social network sites (SNS) have experienced outstanding expansion over the last decade, becoming essential channels for business communication and marketing, with an increasing number of companies that have created their own corporate pages on SNS. A paradigmatic example is Facebook, which is the market leader among all social media with more than 1,550 million users around the world at the end of 2015 (Statista 2016). These applications generate new communication dynamics that influence individuals' decision-making processes. Specifically, SNS allow the publication of user-generated content, giving rise to a particular form of electronic word-of-mouth (e-WOM) (Hennig-Thurau et al. 2004; Kim and Johnson 2016). Thus, the content that some users publish on SNS, either textual or audiovisual, about their experiences with products and brands, may affect other consumers' attitudes and intentions. This phenomenon has attracted great attention from both practitioners and academics and, based on a meta-analysis of previous literature on the topic, King et al. (2014) highlight the need for deeper research into the factors that foster e-WOM, including SNS.

In this sense, this paper intends to contribute to the literature by shedding new light on the factors that determine individuals' intentions to use SNS to share content about their consumption experiences. Given that SNS are technological applications, this paper uses the Unified Theory of Acceptance and Use of Technology 2 (UTAUT2), established by Venkatesh et al. (2012), as a reference framework, and incorporates performance expectancy, effort expectancy, social influence, facilitating conditions, hedonic motivations, and habits in the use of the technology as explanatory variables. This theoretical model was chosen for the following reasons: first, it is a novel theory that is specifically designed to explain and predict technology adoption in consumption contexts, as is the case in individuals' use of SNS to publish contents about their experiences with brands and products. Second, this model offers a global and integrative approach, as it incorporates the main explanatory variables of previous theoretical models about technology acceptance and use. Finally, it has proven to be a successful model for studying technology acceptance and use in a variety of contexts, although the empirical 
evidence about its validity and applicability is very scarce to date and the results obtained are contradictory (Arenas-Gaitán et al. 2015; Baptista and Oliveira 2015).

Despite its wide acceptance in previous research, our study intends to develop the UTAUT2 model in two ways, with the purpose of better understanding the phenomenon under investigation. On the one hand, we establish a revised formulation of this theory, substituting the variable "price value" with the construct "privacy concerns", since SNS are free applications with no economic cost to users. In particular, privacy concerns refer to the perceived potential cost of publishing user-generated content in terms of self-disclosure. On the other hand, in contrast to the UTAUT2, our model incorporates the novelty of examining the interrelations between the variables determining the intention to use SNS to share content about consumption experiences.

In the next section, we provide some background on the UTAUT2 theory and develop our model, which is empirically tested through a quantitative study in the tourism industry. The choice of this context is due to the great influence of SNS on the behavior of tourists and the strategies of destinations (Kwok and Yu 2013; Leung et al. 2013). More concretely, the experiential nature of tourism products and services leads many people to share their consumption experiences with others by publishing opinions, photos, or videos on various electronic applications, including SNS. For its part, tourist destinations use these applications to manage the e-WOM to benefit their image in the marketplace.

\section{BACKGROUND AND RESEARCH HYPOTHESES}

\subsection{UTAUT2 and the Use of SNS to Generate Content}

The UTAUT2 (Venkatesh et al. 2012) is a theoretical model based on the UTAUT (Venkatesh et al. 2003), which aims to provide a rigorous framework specifically designed to explain technology acceptance and use. Whereas the original UTAUT was mainly designed for organizational contexts, the UTAUT2 is primarily focused on consumers and the factors that 
determine their intentions to use (and actual use of) new technologies (Venkatesh et al. 2012). In particular, this theoretical framework introduces three main aspects with regard to its predecessor: 1) redefining the four explanatory variables included in the original UTAUTperformance expectancy, effort expectancy, social influence, and facilitating conditions- to adapt them to consumption contexts; 2) identifying three additional key constructs from prior research on both the general adoption and use of technologies and the consumer adoption and use of technologies; and 3) altering some of the existing relationships in the original formulation of the UTAUT and introducing new relationships.

Regarding the first issue, Venkatesh et al. (2012, pp. 159) define performance expectancy as "the degree to which using a technology will provide benefits to consumers in performing certain activities". They define effort expectancy as "the degree of ease associated with consumers' use of technology", while social influence is conceptualized as "the extent to which consumers perceive that important others (e.g., family and friends) believe they should use a particular technology". Finally, facilitating conditions refer to "consumers' perceptions of the resources and support available to perform a behavior".

Second, the UTAUT2 includes three new explanatory variables in addition to the four constructs included in the original model (Venkatesh et al. 2012): hedonic motivation, price value, and habit. Hedonic motivation is defined as the "fun or pleasure derived from using a technology". Price value is defined as "consumers' cognitive tradeoff between the perceived benefits of the applications and the monetary cost for using them". Habit is defined as "the extent to which people tend to perform behaviors automatically because of learning".

Third, the UTAUT2 reformulates the relationships established in the UTAUT and introduces new relationships to cover the effects of the new explanatory variables included in the model. In particular, according to the UTAUT2, the behavioral intention to use a technology is theorized to be determined by seven explanatory variables: performance expectancy, effort expectancy, 
social influence, facilitating conditions, hedonic motivation, price value, and habit (Venkatesh et al. 2012). Moreover, behavioral intention, facilitating conditions, and habit determine technology use (Venkatesh et al. 2012). The relationships between the variables included in the original formulation of the UTAUT2 are graphically represented in Figure 1.

\section{Figure 1. UTAUT2 - Basic causal structure}

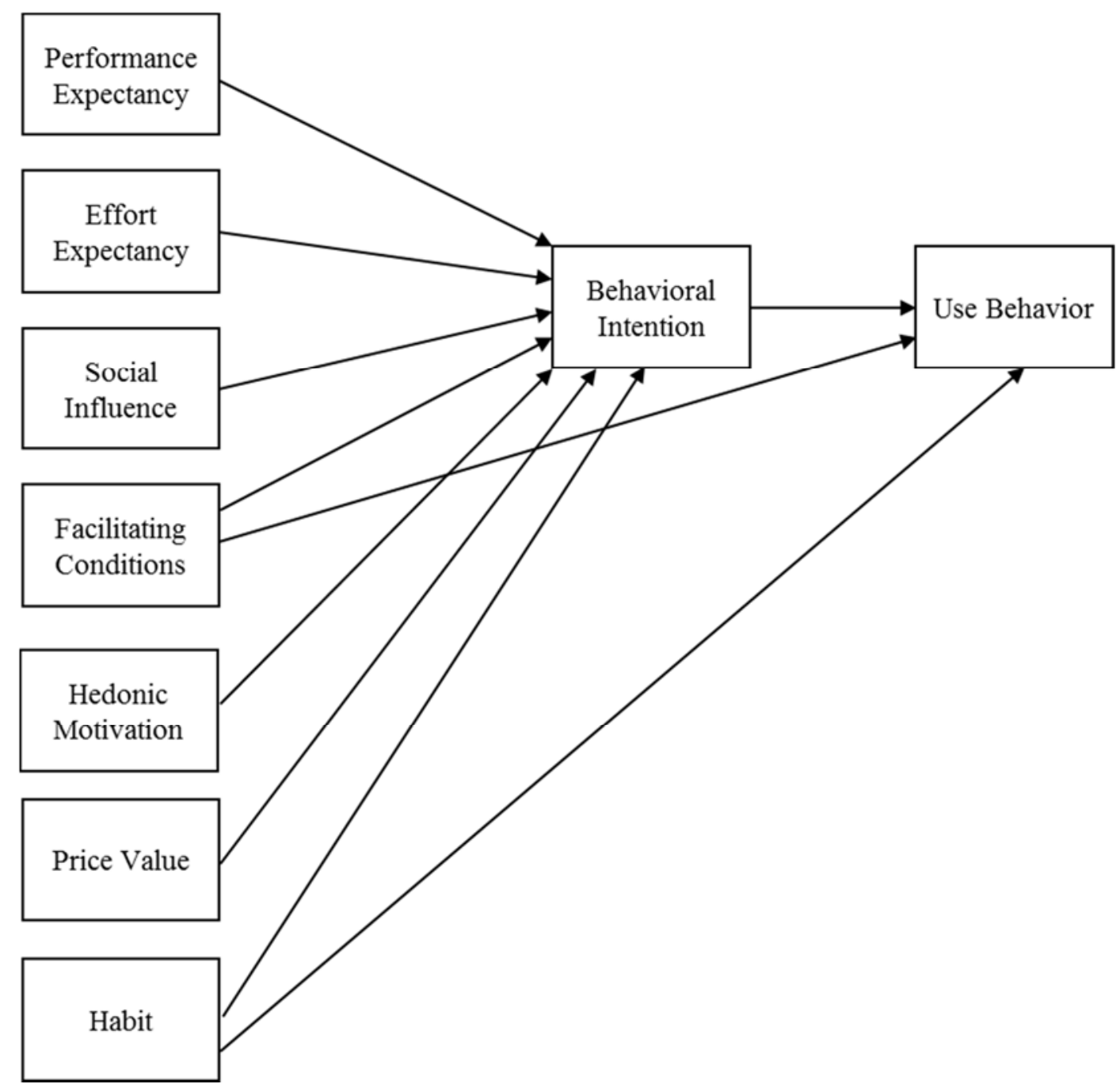

Despite its recent adoption in the literature, the UTAUT2 has already been tested in some studies (Arenas-Gaitán et al. 2015; Baptista and Oliveira 2015), which have confirmed its validity to explain technology adoption in consumption contexts, including the tourism industry (Escobar-Rodríguez and Carvajal-Trujillo 2013; Morosan and DeFranco 2016). However, the 
results obtained in these studies with regard to the effect of the different explanatory variables of the model are very heterogeneous (see Table 1 for a summary of results), and there is still the need for a systematic investigation to make the formulation of the UTAUT2 more precise.

While the UTAUT2 is an appropriate theoretical framework to study the behavior under investigation (i.e., the use of SNS to publish contents about tourism experiences), it cannot be directly applied, given that SNS are free applications with no economic cost to users. Therefore, "price value", in monetary terms, is not a suitable explanatory variable in this specific context. Consequently, we consider the effect of all explanatory variables included in the UTAUT2 on the intention to use SNS to publish contents about experiences, with the exception of the influence of "price value". Accordingly, the following research hypotheses are established:

H1: The performance expectancy in the use of SNS to share user-generated content has a positive influence on behavioral intention.

H2: The effort expectancy in the use of SNS to share user-generated content has a positive influence on behavioral intention.

H3: The social influence regarding the use of SNS to share user-generated content has a positive influence on behavioral intention.

H4: The facilitating conditions perceived in the use of SNS to share user-generated content have a positive influence on behavioral intention.

H5: The hedonic motivation in the use of SNS to share user-generated content has a positive influence on behavioral intention.

H6: The habit of using SNS to share user-generated content has a positive influence on behavioral intention. 
Table 1. Summary of empirical results obtained in previous research based on the UTAUT2

\begin{tabular}{|c|c|c|c|c|c|}
\hline Relationship & $\begin{array}{c}\text { Venkatesh, Thong and } \\
\text { Xu (2012) }\end{array}$ & $\begin{array}{l}\text { Arenas-Gaitán, Peral- } \\
\text { Peral, and Ramón- } \\
\text { Jerónimo (2015) }\end{array}$ & $\begin{array}{c}\text { Baptista and Oliveira } \\
\text { (2015) }\end{array}$ & $\begin{array}{l}\text { Escobar-Rodríguez and } \\
\text { Carvajal-Trujillo (2013) }\end{array}$ & $\begin{array}{c}\text { Morosan and } \\
\text { DeFranco (2016) }\end{array}$ \\
\hline Performance Expectancy $\rightarrow$ Behavioral Intention & Supported & Supported & Supported & Supported & Supported \\
\hline Effort Expectancy $\rightarrow$ Behavioral Intention & Supported & Supported & No supported & Supported & No supported \\
\hline Social Influence $\rightarrow$ Behavioral Intention & Supported & No supported & No supported & No supported & Supported \\
\hline Facilitating Conditions $\rightarrow$ Behavioral Intention & Supported & No supported & No supported & Supported & Supported \\
\hline Hedonic Motivation $\rightarrow$ Behavioral Intention & Supported & No supported & Supported & No supported & Supported \\
\hline Price Value $\rightarrow$ Behavioral Intention & Supported & Supported & No supported & Supported & Supported \\
\hline Habit $\rightarrow$ Behavioral Intention & Supported & Supported & Supported & Supported & Supported \\
\hline Behavioral Intention $\rightarrow$ Use Behavior & Supported & Supported & No supported & Supported & Not tested \\
\hline Facilitating Conditions $\rightarrow$ Use Behavior & Supported & No supported & No supported & Supported & Not tested \\
\hline Habit $\rightarrow$ Use Behavior & Supported & Supported & Supported & Supported & Not tested \\
\hline
\end{tabular}


Nevertheless, beyond "price value," there is another variable directly related to the "cost" to consumers that has been identified as a barrier for technology adoption (e.g., for e-commerce and Internet use) in previous research: privacy loss. In this sense, Joinson et al. (2010) found evidence that privacy concerns influence people's willingness to disclose personal information on a website, acting as a "cost" in terms of privacy. More relevantly, Krasnova et al. (2010) confirmed that perceived privacy risk has a negative effect on consumers' self-disclosure on SNS. Accordingly, users' privacy concerns act as a potential cost in terms of information disclosure, which can negatively influence the acceptance of technology (Herrero et al. 2009). Consequently, we include the variable "privacy concerns", instead of "price value" in the UTAUT2, and propose the following research hypothesis with regard to its effect on users' intentions to use SNS to publish contents about their experiences:

H7: The privacy concerns related to the use of SNS to share user-generated content have a negative effect on behavioral intention.

\subsection{Interrelations among the Explanatory Variables Included in the UTAUT2 and Indirect Effects on the Intention to Use SNS to Share User-generated Content}

In order to obtain a deeper understanding of the determinants of technology adoption and use, this research develops the UTAUT2 by incorporating the interrelations between the explanatory variables in the model that have been identified as robust in previous literature on technology adoption and which affect performance expectancy, effort expectancy, hedonic motivation, and habit of use.

A very well established relationship in the literature on technology adoption is the positive effect of effort expectancy on performance expectancy. The Technology Adoption Model (TAM) (Davis 1989; Davis et al. 1989, 1992) postulates that the perceived ease-of-use of an information system (equivalent to the effort expectancy established by Venkatesh et al. 2003) positively influences its perceived usefulness (equivalent to performance expectancy), which is 
also an antecedent of behavioral intention. Therefore, and in terms of the UTAUT2, effort expectancy would not only have a direct effect on the intention to use a technology (e.g., the use of SNS to share user-generated content) but also an indirect effect through its influence on performance expectancy. The TAM has been widely applied in consumption contexts, and the empirical evidence obtained has confirmed the positive effect of perceived ease-of-use on perceived usefulness - i.e., the effect of effort expectancy on performance expectancy (Ayeh et al. 2013; Chung et al. 2015; Herrero and San Martín 2012; Lowry et al. 2013). Therefore, we establish the following research hypothesis:

H8: The effort expectancy in the use of SNS to share user-generated content has a positive influence on the performance expectancy.

Effort expectancy in the use of a technology (or variables identified as equivalent according to Venkatesh et al. 2003) has been associated with a diversity of variables related to hedonic motivations. Taking the TAM as a theoretical framework, Di Pietro et al. (2012) confirmed the significant effect of perceived ease-of-use of SNS on the enjoyment associated with its use. Furthermore, Lowry et al. (2013) suggested that perceived ease-of-use positively influences the joy in the use of, what they call, hedonic-motivation systems (i.e., systems used primarily to fulfill users' intrinsic motivations). In particular, they defined this joy as "the extent to which the activity of using the computer is perceived to bring about pleasure and joy for their own sake, apart from any anticipated performance consequences". In contrast, Ayeh et al. (2013) proposed that perceived enjoyment has a positive effect on perceived ease-of-use. However, most previous studies show that the effort expectancy in an information system influences the hedonic motivation in its use (or equivalent variables). In consequence, technologies that require more effort will be perceived as less fun or enjoyable (i.e., users will have a lower hedonic motivation), which led us to propose the following research hypothesis:

H9: The effort expectancy in the use of SNS to share user-generated content has a positive influence on the hedonic motivations. 
Previous research has also suggested a causal relationship between effort expectancy and habit, which is quite intuitive, however, the empirical evidence available for this is very scarce, particularly in consumption contexts. Pillet and Carillo (2016) found a significant and positive effect of the perceived ease-of-use of a technology on the habit of using it over time, but in an organizational context. Although there is no empirical evidence on the influence of effort expectancy on the habit of use, it is reasonable to think that a higher perceived ease-of-use in using SNS to share user-generated content will lead to a stronger habit. Accordingly, consistent with Pillet and Carillo (2016), we propose the following research hypothesis:

H10: The effort expectancy in the use of SNS to share user-generated content has a positive influence on the habit of use.

The habit of using a technology has also been related to hedonic motivations. In particular, according to Chiu et al. (2012), the hedonic motivations in the use of a technology directly influence the habit of using it and, through this variable, the intention to use that technology in the future. Therefore, the users' perception of fun and enjoyment in the use of the technology would not only have a direct influence on the intention to use it (as established in the UTAUT2) but also an indirect effect through habit of use. That is to say, if users have stronger hedonic motivations in the use of SNS to share user-generated content, they will have a stronger habit of use. In consequence, we propose the following research hypothesis:

H11: The hedonic motivation in the use of SNS to share user-generated content has a positive influence on the habit of use.

Finally, the previous literature has suggested that the habit of using a technology is an antecedent of its performance expectancy. In particular, using the TAM as a theoretical framework, Liao et al. (2011) obtained empirical evidence supporting a positive effect of habit on perceived usefulness. According to their results, a habitual use of SNS to share usergenerated content will lead to a superior performance expectancy in the use of this technology. In consequence, we establish the following research hypothesis: 
H12: The habit of using SNS to share user-generated content has a positive influence on performance expectancy.

The research hypotheses proposed give rise to the research model that is graphically represented in Figure 2.

Figure 2. Research model

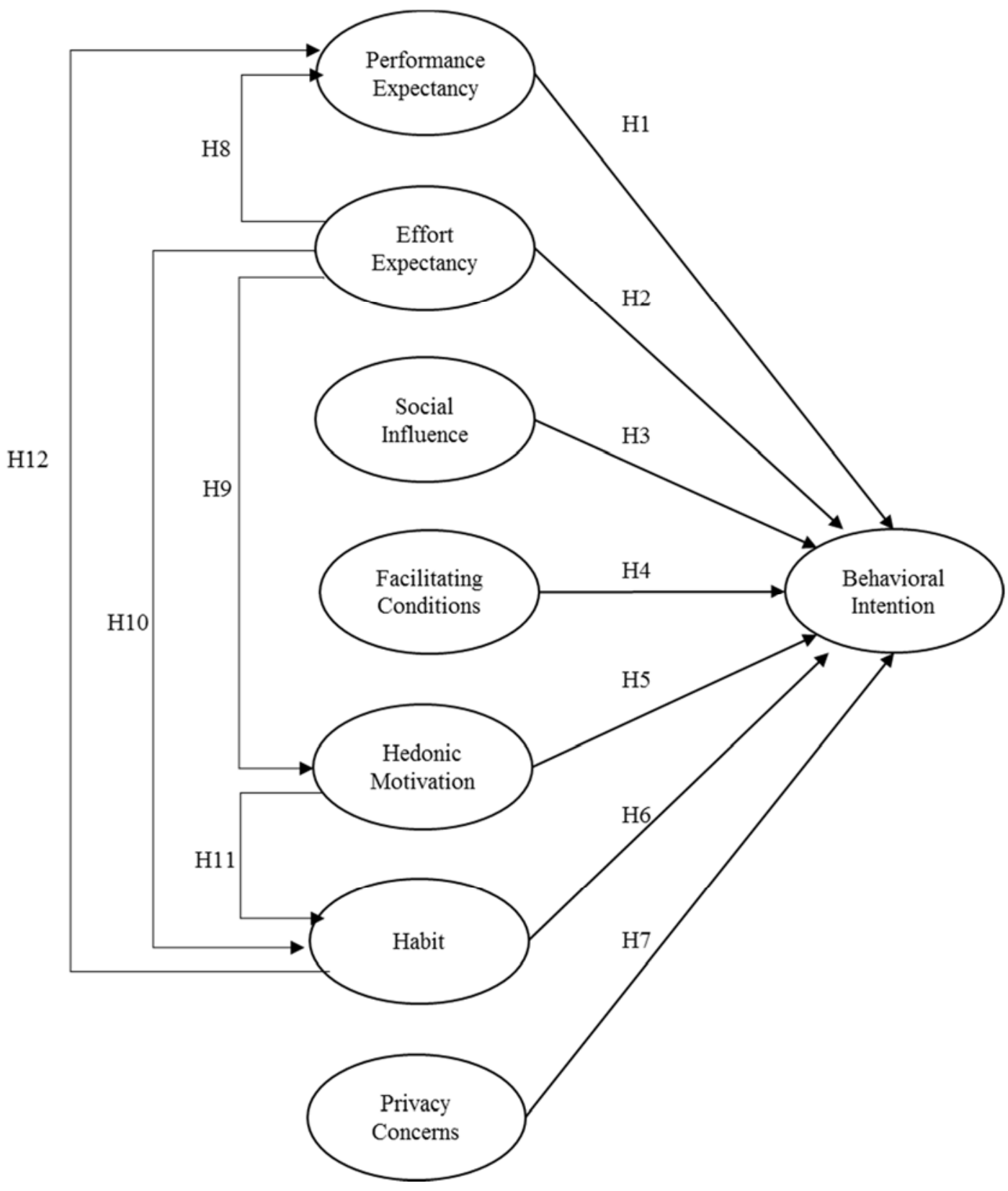




\section{METHOD}

\subsection{Measurement}

In order to test our research hypotheses, we developed a quantitative study, based on a survey for tourists visiting a Spanish destination who have a personal profile on SNS (specifically on Facebook, given its widespread use worldwide), so that they could potentially publish content about their destination experiences. Data collection was carried out using a questionnaire, where the variables of the model were operationalized using multi-item measures. Individuals were asked for their responses using a seven-point Likert scale (the items for each of the measurement scales are summarized in Appendix A). In particular, the original instrument proposed by Venkatesh et al. (2012) served as the basis for developing the measurement scales for behavioral intention and its main explanatory factors (i.e., performance expectancy, effort expectancy, social influence, facilitating conditions, hedonic motivations, and habit). In the case of privacy concerns, which is not included in the original formulation of the UTAUT2, we adapted the scale of privacy risk, developed by Herrero et al. (2009), to our research context.

\subsection{Sampling Design}

The target population of quantitative research consisted of tourists, above 18 years of age, who were visiting a tourist destination in Spain. Because the size of this target population was unknown and there was no census available, the survey sample was selected using a nonrandom sampling procedure. Data collection was conducted through a personal survey, which was conveniently administered during the summer season at the destination's International Airport and at the most important tourist attractions. In order to minimize the possible bias due to the sampling procedure, the interviewers were instructed to administer the questionnaire to tourists who had an active profile on SNS during their visit to the destination. This requirement was established to ensure that respondents were familiarized with this technology and could potentially use it to publish contents about their tourism experiences in the short term. Finally, 537 valid surveys were collected (the main characteristics of respondents are shown in Table 2). 
Table 2. Sample description

\begin{tabular}{lccc}
\hline Variable & $\%$ & Variable & $\%$ \\
\hline Gender & 47.9 & Occupation & \\
\multicolumn{1}{l}{ Male } & 52.1 & Employed / Worker & 49.7 \\
\multicolumn{1}{l}{ Female } & & Student & 29.3 \\
Age & 31.5 & Housework & 7.7 \\
& & Unemployed/Retired & 13.3 \\
24 years or less & 32.0 & Education level & \\
$25-34$ years & 17.7 & Less than primary & 3.4 \\
$35-44$ years & 12.7 & Primary & 8.6 \\
$45-54$ years & 4.1 & Secondary & 40.2 \\
$55-64$ years & 2.0 & University & 47.9 \\
65 or more years & &
\end{tabular}

\subsection{Statistical Analysis}

Harman's single-factor test was conducted (IBM-SPSS) to check for common method variance (CMV). In other words, a check was made on whether the correlation among variables was significantly influenced by their common measurement source (Chang et al. 2010). The results of this analysis indicated that the items load into more than one factor and, therefore, they are not concentrated in any one general factor. Consequently, we can indicate that CMV does not significantly influence this quantitative research. The descriptive statistics of the variables are summarized in Appendix B.

\section{RESULTS}

The statistical analyses were developed using the structural equation modeling (SEM) methodology with EQS 6.1software. First, the measurement model was estimated to test the psychometric properties (i.e. reliability and validity) of the measurement scales. Next, the structural model was estimated in order to contrast the research hypotheses. Finally, and following a well-established approach in SEM (Bagozzi and Yi 1988; Martinez-Lopez et al. 
2013), rival models were also estimated to assess the validity of the structural model hypothesized in our research.

\subsection{Estimation of the Measurement Model: Confirmatory Factor Analysis}

The results obtained for the goodness-of-fit indices show a correct specification for the measurement model. In particular, the results summarized in Table 3 confirm that the BBNFI, BBNNFI, CFI, and IFI statistics clearly exceed the recommended minimum value of 0.9. For its part, RMSEA is located within the maximum limit of 0.08 , while, as normed, $\chi^{2}$ has a value clearly under the limit of 3.0 (Hair et al. 2010).

The reliability of the measurement scales was evaluated using Cronbach's Alpha, compound reliability, and AVE coefficients (Bagozzi and Yi 1988). The values of these statistics are, in every case, clearly above the required minimum values (Hair et al. 2010), thus supporting the inner reliability of the proposed constructs (Table 3). The convergent validity of the scales was also confirmed (Table 3), since all items are significant to a confidence level of $95 \%$ and their standardized lambda coefficients are higher than 0.5 (Steenkamp and Van Trijp 1991). The discriminant validity of the scales was tested following the procedure proposed by Fornell and Larcker (1981). The results, summarized in Table 4, show that the AVE coefficients are, in all cases, higher than the squared correlation between each pair of constructs, thus confirming the discriminant validity of the measurement scales. 
Table 3. Confirmatory factor analysis

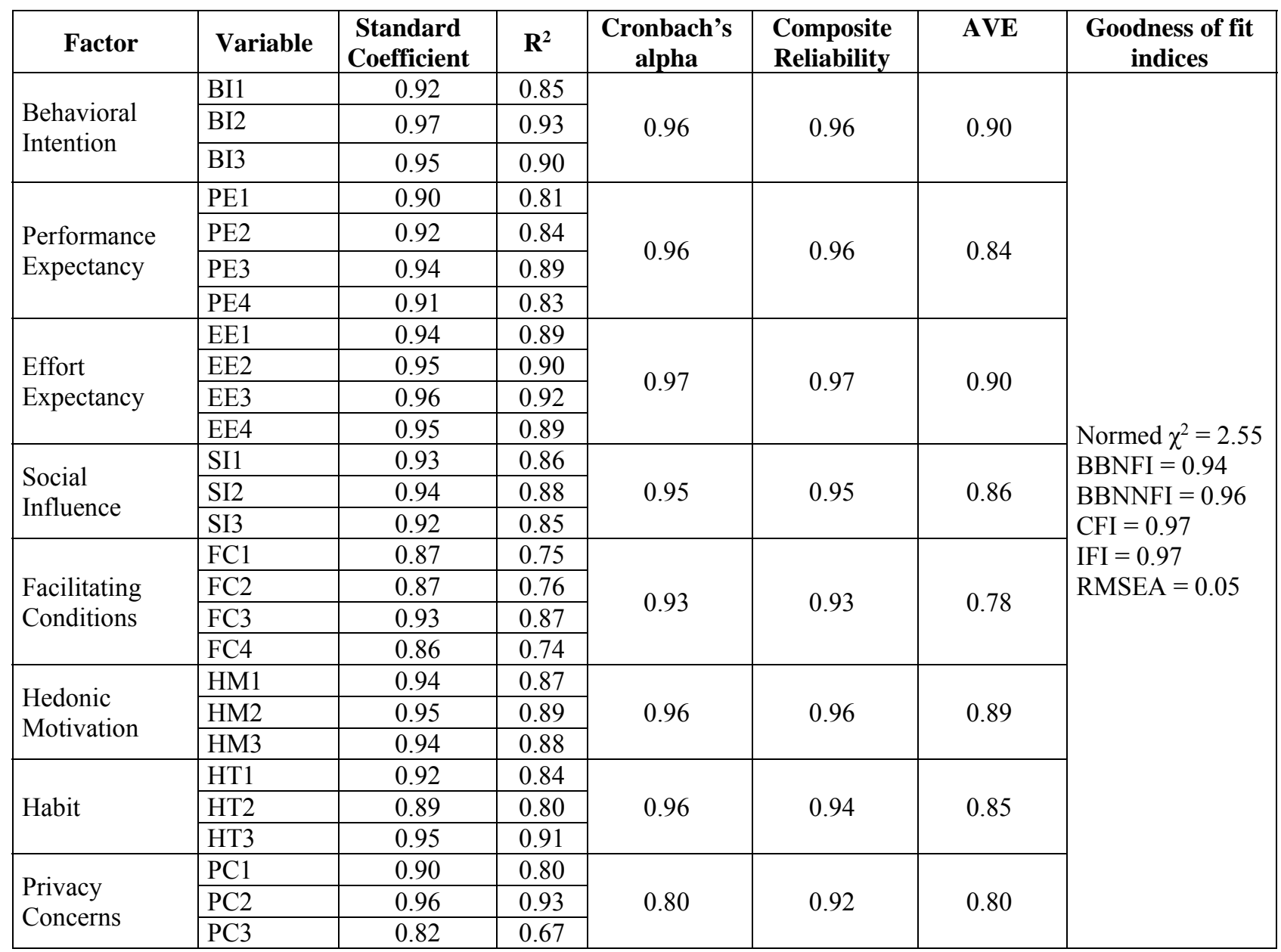

Table 4. Squared correlation between pairs of latent variables and AVE coefficients

\begin{tabular}{|l|c|c|c|c|c|c|c|c|}
\hline & $\begin{array}{c}\text { Behavioral } \\
\text { intention }\end{array}$ & $\begin{array}{c}\text { Performance } \\
\text { Expectancy }\end{array}$ & $\begin{array}{c}\text { Effort } \\
\text { Expectancy }\end{array}$ & $\begin{array}{c}\text { Social } \\
\text { nffluence }\end{array}$ & $\begin{array}{c}\text { Facilitating } \\
\text { Conditions }\end{array}$ & $\begin{array}{c}\text { Hedonic } \\
\text { Motivation }\end{array}$ & Habit & $\begin{array}{c}\text { Privacy } \\
\text { Concerns }\end{array}$ \\
\hline $\begin{array}{l}\text { Behavioral } \\
\text { intention }\end{array}$ & $\mathbf{0 . 9 0}$ & & & & & & & \\
\hline $\begin{array}{l}\text { Performance } \\
\text { Expectancy }\end{array}$ & 0.66 & $\mathbf{0 . 8 4}$ & & & & & & \\
\hline $\begin{array}{l}\text { Effort } \\
\text { Expectancy }\end{array}$ & 0.52 & 0.61 & $\mathbf{0 . 9 0}$ & & & & & \\
\hline $\begin{array}{l}\text { Social } \\
\text { Influence }\end{array}$ & 0.28 & 0.30 & 0.35 & $\mathbf{0 . 8 6}$ & & & & \\
\hline $\begin{array}{l}\text { Facilitating } \\
\text { Conditions }\end{array}$ & 0.32 & 0.49 & 0.64 & 0.38 & $\mathbf{0 . 7 8}$ & & & \\
\hline $\begin{array}{l}\text { Hedonic } \\
\text { Motivation }\end{array}$ & 0.61 & 0.48 & 0.45 & 0.34 & 0.36 & $\mathbf{0 . 8 9}$ & & \\
\hline Habit & 0.55 & 0.38 & 0.40 & 0.21 & 0.28 & 0.62 & $\mathbf{0 . 8 5}$ & \\
\hline $\begin{array}{l}\text { Privacy } \\
\text { Concerns }\end{array}$ & 0.08 & 0.08 & 0.06 & 0.05 & 0.05 & 0.12 & 0.08 & $\mathbf{0 . 8 0}$ \\
\hline
\end{tabular}




\subsection{Estimation of the Hypothesized Structural Model}

Once the psychometric properties of the scales were examined, the causal model was estimated using the robust maximum likelihood estimation procedure to avoid potential problems related to the non-normality of data. The results obtained in the first estimation of the model only support the significant direct effect on behavioral intention of three of the explanatory variables included in the original formulation of the UTAUT2: performance expectancy (hypothesis H1), hedonic motivation (hypothesis H5), and habit (hypothesis H6). In contrast, direct influences on behavioral intention of effort expectancy (hypothesis H2), social influence (hypothesis H3), facilitating conditions (hypothesis H4), and privacy loss (hypothesis H7) are not supported.

Regarding the indirect effects of the explanatory variables on the intention to use SNS to share user-generated content, all research hypotheses proposed are supported (H8 to H12). More concretely, effort expectancy has a significant effect on performance expectancy (hypothesis H8), hedonic motivation (hypothesis H9), and habit (hypothesis H10); hedonic motivation significantly influences habit (hypothesis H11); and habit exerts a significant effect on performance expectancy (hypothesis H12).

Applying the model development approach (Hair et al. 2010), the original model was reformulated (Figure 3) to exclude the non-significant relationships. The goodness-of-fit indices support the correct definition of the revised model (normed $\chi^{2}=3.01$; BBNFI $=0.97$; BBNNFI $=0.97 ; \mathrm{CFI}=0.98 ; \mathrm{IFI}=0.98 ; \mathrm{RMSEA}=0.06)$ and a substantial percentage of the variance of the dependant variables are explained $\left(R^{2}\right.$ behavioural intention $=0.77 ; R^{2}$ performance expectancy $=0.65 ; \mathrm{R}^{2}$ hedonic motivation $=0.45 ; \mathrm{R}^{2}$ habit $\left.=0.65\right)$. 
Figure 3. Estimation of the revised model

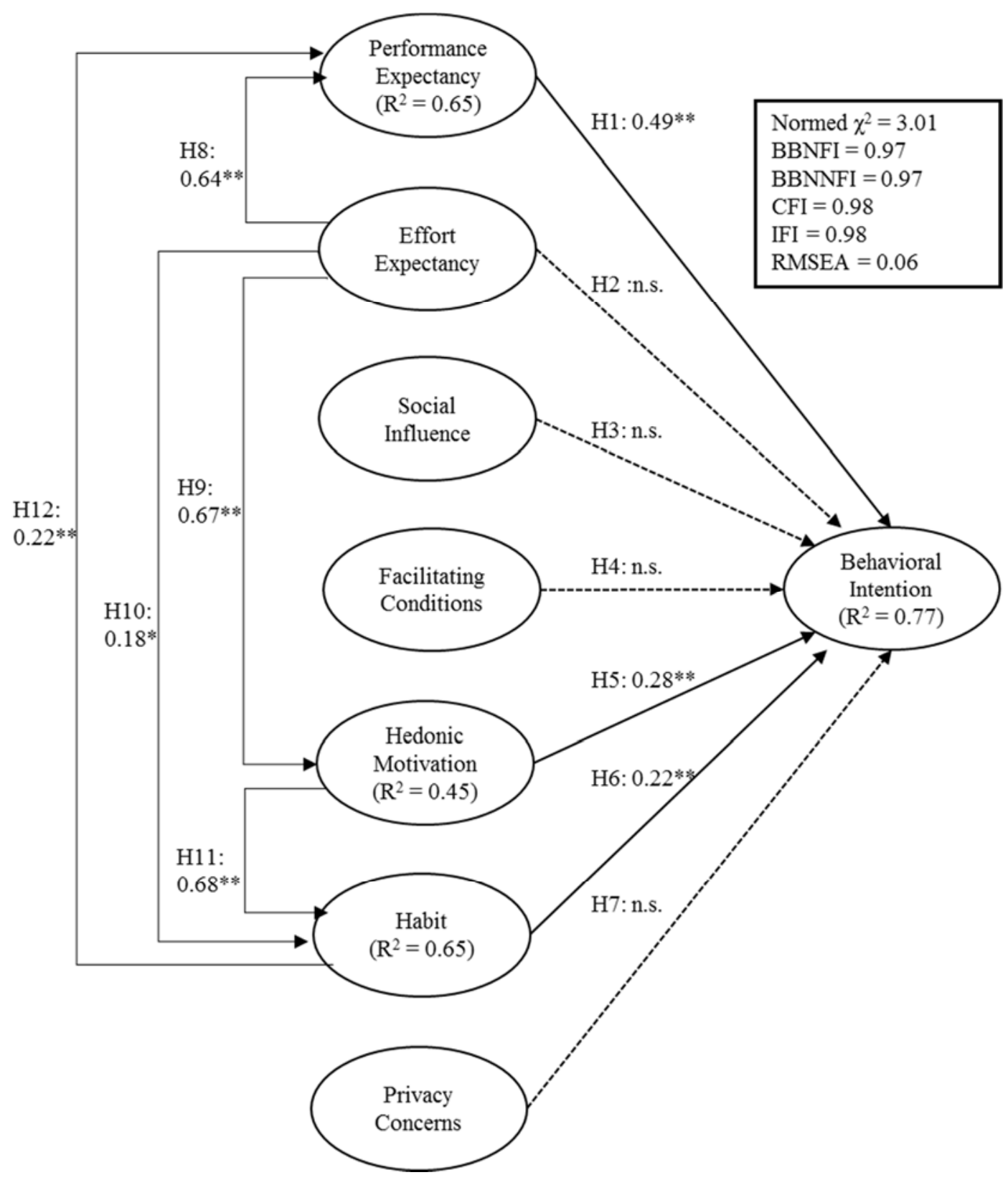

\subsection{Estimation of Rival Models}

Different authors have highlighted the importance of competitive modelling in assessing the validity of a hypothesized structural model (Bagozzi and Yi 1988; Martinez-Lopez et al. 2013). More concretely, the estimation of rival models allows for comparison of different models, with the aim of selecting the most valid (Martinez-Lopez et al. 2013). This research considers two alternative theoretical models: 1) the original formulation of the UTAUT2 (without the indirect effects reflected in hypotheses $\mathrm{H} 8$ to H12); and 2) the re-specified model resulting from 
eliminating the non-significant effects from the original formulation of the UTAUT2 (i.e., excluding from the analysis the relationships reflected in hypotheses $\mathrm{H} 2, \mathrm{H} 3, \mathrm{H} 4$, and $\mathrm{H} 7$ ). The comparison of the research model with these two alternatives will reveal the advantage of the first over the original UTAUT2 (with only direct effects), even once refined by eliminating the non-significant direct relationships.

Table 5 summarizes the goodness-of-fit indices, the Akaike Information Criterion (AIC) (Akaike 1987), and the standardized coefficients of the relationships corresponding to the two rival models analysed. The goodness-of-fit indices for the two rival models considered are clearly worse than the ones obtained for the hypothesized model. Specifically, the values of the AIC (chi-square adjusted for the number of estimated parameters) obtained for the rival models are significantly higher than the AIC value for our model. In the case of the original UTUAT2, the poor fit of the theoretical model to the data can be partially explained by the estimation of non-significant relationships. Nevertheless, the results obtained for the revised UTAUT2 model (excluding non-significant relationships) show that goodness-of-fit indices are closer to the recommended values but worse than those obtained for the hypothesized model. 
Table 5. Evaluation of rival models

\begin{tabular}{|c|c|c|c|}
\hline & $\begin{array}{l}\text { Theoretical model } \\
\text { Revised UTAUT2 }\end{array}$ & $\begin{array}{l}\text { Alternative Model } 1 \\
\text { UTAUT2 (Original) }\end{array}$ & $\begin{array}{c}\text { Alternative Model } 2 \\
\text { UTAUT2 (Re-specified) }\end{array}$ \\
\hline \multicolumn{4}{|l|}{ Goodness of fit indices: } \\
\hline Normed $\chi^{2}$ & 3.01 & 7.37 & 11.96 \\
\hline BBNFI & 0.97 & 0.83 & 0.90 \\
\hline BBNNFI & 0.97 & 0.83 & 0.89 \\
\hline IFI & 0.98 & 0.85 & 0.91 \\
\hline CFI & 0.98 & 0.85 & 0.91 \\
\hline RMSEA & 0.06 & 0.11 & 0.14 \\
\hline Akaike Information Criterion (AIC) & 112.45 & 1705.08 & 617.57 \\
\hline H1 :Performance Expectancy $\rightarrow$ Behavioral Intention & $0.49 * *(\mathrm{t}=10.88)$ & $0.60 * *(\mathrm{t}=15.30)$ & $0.62 * *(t=15.60)$ \\
\hline H2: Effort Expectancy $\rightarrow$ Behavioral Intention & - & $0.07(\mathrm{t}=1.93)$ & - \\
\hline H3: Social Influence $\rightarrow$ Behavioral Intention & - & $0.05(\mathrm{t}=1.56)$ & - \\
\hline H4: Facilitating Conditions $\rightarrow$ Behavioral Intention & - & $-0.07(\mathrm{t}=-1.91)$ & - \\
\hline H5: Hedonic Motivation $\rightarrow$ Behavioral Intention & $0.28 * *(\mathrm{t}=5.05)$ & $0.36^{* *}(\mathrm{t}=10.90)$ & $0.38 * *(\mathrm{t}=11.35)$ \\
\hline H6: Habit $\rightarrow$ Behavioral Intention & $0.22 * *(\mathrm{t}=4.32)$ & $0.29 * *(\mathrm{t}=10.47)$ & $0.30 * *(\mathrm{t}=10.66)$ \\
\hline H7: Privacy Concerns $\rightarrow$ Behavioral Intention & - & $-0.002(\mathrm{t}=-.07)$ & - \\
\hline H8: Effort Expectancy $\rightarrow$ Performance Expectancy & $0.64 * *(\mathrm{t}=12.77)$ & & \\
\hline H9: Effort Expectancy $\rightarrow$ Hedonic Motivation & $0.67 * *(\mathrm{t}=15.54)$ & & \\
\hline H10: Effort Expectancy $\rightarrow$ Habit & $0.18 * *(\mathrm{t}=4.07)$ & & \\
\hline H11: Hedonic Motivation $\rightarrow$ Habit & $0.68 * *(\mathrm{t}=15.36)$ & & \\
\hline H12: Habit $\rightarrow$ Performance Expectancy & $0.22 * *(\mathrm{t}=6.21)$ & & \\
\hline
\end{tabular}

$* *$ Standardized coefficient and $\mathrm{p}$-value $<0.05$ 


\section{DISCUSSION}

\subsection{Theoretical Implications}

This research has several relevant theoretical implications, since the research topic (i.e. factors that determine individuals' intentions to use SNS to share content about their consumption experiences) has been scarcely researched to date (Yoo and Gretzel 2011; Bilgihan et al. 2016). First, our study shows that behavioral intention is directly influenced by performance expectancy, hedonic motivation, and the habit of using SNS to share user-generated content (e.g., opinions, videos, and/or pictures). Accordingly, the use of SNS is influenced by both utilitarian and hedonic factors, so the individuals need to find the technology useful and fun. Additionally, habit plays a relevant role, given that future intention to use SNS to share usergenerated content is directly influenced by previous experience with this behavior.

Together with these direct effects, our research shows that effort expectancy, hedonic motivation, and habit have a significant effect on behavioral intention through their influence on other explanatory variables. Specifically, effort expectancy exerts a direct effect on performance expectancy, hedonic motivation, and habit, so it is a very relevant determinant of the intention to use SNS to share user-generated content, even though it has no direct influence on this construct. Similarly, hedonic motivation and habit also exert an indirect and sequential effect on behavioral intention, since hedonic motivation reinforces the habit of using SNS to publish contents, and this increases the performance expectancy of the technology.

On the contrary, our results show that effort expectancy, social influence, facilitating conditions, and privacy concerns have no significant direct influence on the intention to use SNS to share user-generated content. In our opinion, the lack of relevance of these explanatory variables could be due to the specific characteristics of the technology studied. On the one hand, the nonsignificant influence of facilitating conditions on the intention to use SNS to share usergenerated content may be caused by the fact that they are readily available to users and neither foster nor inhibit the behavior. On the other hand, the use of SNS to publish content is widely 
accepted at present, yet this does not necessarily provide a motive to do so. Thus, given that social influence regarding the use of SNS to share user-generated content is generally positive, it does not act as an inhibitor of the behavior, but it does not foster it either.

The non-significant influence of privacy concerns deserves a specific justification, given that we proposed the inclusion of this variable in the UTAUT2 in substitution for price value. In this sense, given that the use of SNS to publish content does not imply an economic cost, we argued that there could be a cost for users in terms of privacy risk (Herrero et al. 2009; Krasnova et al. 2010). However, according to our results, consumers assume this inconvenience as a necessary condition to share their experiences with other people, and privacy concerns do not inhibit the use of SNS to publish content.

From a wider perspective, the results obtained confirm the validity of the UTAUT2 to explain the intention to use information technology in consumer contexts; however, they also reveal the need to revise its formulation. In this sense, the empirical evidence obtained is consistent with previous research based on the UTAUT2, which also shows that only some of the explanatory variables included in the model have a significant effect on behavioral intention (Arenas-Gaitán et al. 2015; Baptista and Oliveira 2015; Escobar-Rodríguez and Carvajal-Trujillo 2013; Morosan and DeFranco 2016). Therefore, although this theoretical framework is certainly valuable to study technology adoption in consumer contexts, more systematic investigation is needed to improve the formulation of the UTAUT2 and define a more parsimonious and consistent theory.

Moreover, our research makes a relevant contribution to the development and refinement of the UTAUT2, as it clearly shows the need to include the interrelationships between the explanatory variables in the model. In this sense, the empirical evidence obtained confirms the existence of strong causal relationships between the explanatory variables of behavioral intention, and, therefore, the coexistence of both direct and indirect effects in the model. As a result, the 
consideration of these interrelations allows for a deeper understanding of the factors determining the use of a technology and improves the fit of the theoretical model to the data (i.e., to the real effects of the variables studied on user behavior).

\subsection{Practical Implications}

The empirical evidence obtained in this research also has important implications from a practical perspective. First, our results provide organizations with interesting insights for developing strategies for encouraging the generation of content on SNS by consumers, for instance, by focusing on making the process more effective, easy, and enjoyable. This can be done through the corporate profile on the SNS, by providing content that is interesting for users to share (e.g., pictures or videos), by facilitating the users' publication of content on the corporate profile, and by sharing the contents published by users in their own profiles on the SNS or on other pages. In this sense, the lack of a significant effect of privacy concerns found in our research suggests a good opportunity in this field, as users seem to be relatively open to information disclosure (e.g., publishing content about experiences).

From the perspective of SNS companies, our results are useful for developing strategies for intensifying the use of their platforms to publish content about experiences. This will have positive consequences for the SNS companies in two ways. First, the publication of more content on experiences will enrich the SNS, as they are assets to be consumed by other users, thus increasing the value of the experience within the platform. Second, this user-generated content also increases the potential of the SNS for marketing purposes, as it is a form of eWOM coming from a source that is attractive to potential advertisers. In this sense, our results show that the development of more user-friendly SNS, by making the publication process easier and more enjoyable, can lead to more user-generated content. 


\subsection{Limitations and Further Research}

This study has several minor limitations. First, the dependent variable of our model (i.e., intention to use SNS to share user-generated content) is subjectively measured by capturing users' perceptions in relation to their future behavior. Although this methodological approach has been widely used in past research on technology adoption (Bilgihan et al. 2016; San Martín and Herrero 2012), Venkatesh et al. $(2003,2012)$ recommend considering the effective behavior of usage. As such, it would be very interesting to jointly examine the intention to use the technology and the effective behavior of use in companies.

Second, our research only focuses on the tourism industry, so it would be interesting to replicate our model in different contexts (e.g., goods or other services) for comparative analysis. Nevertheless, the influence of SNS has been especially important in the tourism industry (Kwok and $\mathrm{Yu}$ 2013; Leung et al. 2013). Accordingly, we consider the sector chosen for this study as a good benchmark for understanding the use of SNS to publish content on experiences in general. Another limitation of this study is the use of a non-random sampling procedure, which could limit the generalization of the empirical results. However, the sample size and the similarity between the target population and the sample, in terms of gender and education, provide evidence of the representativeness of the survey sample.

Finally, the findings of this study raise several questions for future research in relation to the adoption of technologies in consumer contexts in general, and specifically about the factors that influence the use of SNS to publish content. First, as previously mentioned, more research is needed to develop and refine the UTAUT2 in order to get to a more parsimonious and consistent formulation that is applicable to any technology. Additionally, more theoretical reflection and empirical evidence is needed regarding the role of price value or other constructs related to cost in the UTAUT2. Finally, it would be interesting to analyze which attributes or advantages of SNS lead to higher performance expectancy, better effort expectancy, and more fun in the use of SNS to share user-generated content. 


\section{REFERENCES}

Arenas-Gaitán, J., Peral-Peral, B., and Ramón-Jerónimo, M.A. 2015. “Elderly and Internet Banking: An Application of UTAUT2," Journal of Internet Banking and Commerce (20:1). Ayeh, J.K., Au, N., and Law, R. 2013. "Predicting the intention to use consumer-generated media for travel planning," Tourism Management (35), pp. 132-143.

Bagozzi, R.P., and Yi, Y. 1988. "On the evaluation of structural equation models," Journal of the Academy of Marketing Science (16:1), pp. 74-94.

Baptista, G., and Oliveira, T. 2015. "Understanding mobile banking: The unified theory of acceptance and use of technology combined with cultural moderators," Computers in Human Behavior (50), pp. 418-430.

Bilgihan, A., Barreda. A., Okumus, F., and Nusair, K. 2016. "Consumer perception of knowledge-sharing in travel-related Online Social Networks," Tourism Management (52), pp. 287-296.

Chang, S-J., van Witteloostuijn, A., and Eden, L. 2010. "From the editors: Common method variance in international business research," Journal of International Business Studies (41), pp. $178-184$.

Chiu, C-M., Hsu, M-H., Lai, H.L., and Chang, C-M. 2012. "Re-examining the influence of trust on online repeat purchase intention: The moderating role of habit and its antecedents," Decision Support Systems (53), pp. 835-845

Chung, N., Han, H. and, Joun, Y. 2015. “Tourists' intention to visit a destination: The role of augmented reality (AR) application for a heritage site," Computers in Human Behavior (50), pp. 588-599.

Davis, F.D. 1989. "Perceived usefulness, perceived ease of use and user acceptance of information technology," MIS Quarterly (13:3), pp. 319-339.

Davis, F.D., Bagozzi, R.P., and Warshaw, P.R. 1989. "User acceptance of computer technology: A comparison of two theoretical models," Management Science (35:8), pp. 982-1003. 
Davis, F.D., Bagozzi, R.P., and Warshaw, P.R. 1992. "Extrinsic and intrinsic motivation to use computers in the workplace," Journal of Applied Social Psychology (22:14), pp. 1111-1132. Di Pietro, L., Di Virgilio, F., and Pantano, E. 2012. "Social network for the choice of tourist destination: attitude and behavioural intention," Journal of Hospitality and Tourism Technology (3:1), pp. 60-76.

Escobar-Rodríguez, T., and Carvajal-Trujillo, E. 2013. "Online drivers of consumer purchase of website airline tickets," Journal of Air Transport Management (32), pp. 58-64.

Fornell, C., and Larcker, D.F. 1981. "Evaluating structural equation models with unobservable variables and measurement error," Journal of Marketing Research (18:1), pp. 39-50.

Hair, J.F., Anderson, R.E., Tatham, R.L., and Black, W.C. 2010. Multivariate Data Analysis, 7th edition. Prentice Hall: New Jersey.

Hennig-Thurau, T., Gwinner, K.P., Walsh, G., and Gremler, D.D. 2004. "Electronic Word-ofMouth Via Consumer-Opinion Platforms: What Motivates Consumers to Articulate Themselves on the Internet?", Journal of Interactive Marketing (18:1), pp. 38-52.

Herrero, A.; Rodríguez, I.; García de los Salmones, M.M. 2009. ”The influence of perceived risk on Internet shopping behaviour: A multidimensional perspective," Journal of Risk Research (12:2), pp. 259-277.

Herrero, A., and San Martín, H. 2012. "Developing and testing a global model to explain the adoption of websites by users in rural tourism accommodations," International Journal of Hospitality Management (31:4), pp. 1178-1186.

Joinson, A.N., Reips, U-D., Buchanan, T. and Schofield, B.P. 2010. "Privacy, Trust, and SelfDisclosure Online," Human-Computer Interaction (25:1), pp. 1-24.

Kim, A.J. and Johnson, K.K.P. 2016. "Power of consumers using social media: Examining the influences of brand-related user-generated content on Facebook," Computers in Human Behavior (58), pp. 98-108.

King, R.A., Racherla, P., and Bush, V.D. 2014. "What We Know and Don't Know About Online Word-of-Mouth: A Review and Synthesis of the Literature", Journal of Interactive Marketing (28), pp. 167-183 
Krasnova, H., Spiekermann, S., Koroleva, K., and Hildebrand, T. 2010. “Online social networks: why we disclose," Journal of Information Technology (25), pp. 109-125

Kwok, L. and Yu, B. 2013. "Spreading social media messages on Facebook: An analysis of restaurant business-to-consumer communications," Cornell Hospitality Quarterly (54), pp. 8494.

Leung, D., Law, R., van Hoof, H., and Buhalis, D. 2013. "Social Media in Tourism and Hospitality: A Literature Review," Journal of Travel \& Tourism Marketing (30), pp. 3-22. Liao, C., To, P.L., Liu, C-C., Kuo, P-Y., and Chuang, S-H. 2011. "Factors influencing the intended use of web portals," Online Information Review (35:2), pp. 237-254.

Lowry, P.B., Gaskin, J.E., Twyman, N.W., Hammer, B., and Roberts, T.L. 2013. “Taking "Fun and Games" Seriously: Proposing the Hedonic-Motivation System Adoption Model (HMSAM)," Journal of the Association for Information Systems (14:11), pp. 617-671. Martinez-Lopez, F.J., Gázquez-Abad, J.C., and Sousa, C.M.P. 2013. "Structural equation modelling in marketing and business research. Critical issues and practical recommendations," European Journal of Marketing (47:1/2), pp. 115-152.

Morosan, C., and DeFranco, A. 2016. "It's about time: Revisiting UTAUT2 to examine consumers' intentionsto use NFC mobile payments in hotels," International Journal of Hospitality Management (53), pp. 17-29.

Pillet, J.C., and Carillo, K.D.A. 2016. "Email-free collaboration: An exploratory study on the formation of new work habits among knowledge workers," International Journal of Information Management (36), pp. 113-125

San Martín, H. and Herrero, A. 2012. "Influence of the user's psychological characteristics on the online purchase of rural accommodation: Integrating innovativeness to the UTAUT framework," Tourism Management (33:2), pp. 341-350.

Statista 2016. Social Media \& User-Generated Content. Global social networks ranked by number of users. Available online: http://www.statista.com/statistics/272014/global-socialnetworks-ranked-by-number-of-users/. 
Steenkamp, J.E.M., and Van Trijp, H.C.M. 1991. "The use of Lisrel in validating marketing constructs," International Journal of Research in Marketing (8:4), pp. 283-299.

Venkatesh, V., Morris, M.G., Davis, G.B., and Davis, F.D. 2003. “User acceptance of information technology: Toward a unified view," MIS Quarterly (27), pp. 425-478.

Venkatesh, V., Thong, J.Y.L., and Xu, X. 2012. "Consumer acceptance and use of information technology: Extending the Unified Theory of Acceptance and Use of Technology," MIS Quarterly (36:1), pp. 157-178.

Yoo, K.H., and Gretzel, U. 2011. "Influence of personality on travel-related consumer generated media creation," Computers in Human Behavior (27:2), pp. 609-621. 


\section{APPENDIX A. MEASUREMENT SCALES}

\section{Intention to use SNS as communication tools}

BI1 - I intend to use SNS to publish content about my tourism experiences during this trip

BI2 - I will probably use SNS to publish content about my tourism experiences during this trip.

BI3 - I decided to use SNS to publish content about my tourism experiences during this trip.

\section{Performance expectancy}

PE1 - SNS are very useful for publishing content about my tourism experiences.

PE2 - The use of SNS enables me to publish content about my tourism experiences more quickly.

PE3 - The use of SNS increases my efficiency in publishing content about my tourism experiences.

PE4 - The use of SNS improves my performance in publishing content about my tourism experiences.

\section{Effort expectancy}

EE1 - The use of SNS to publish content about my tourism experiences is simple for me.

EE2 - The use of SNS to publish content about my tourism experiences is an activity in which I consider myself skillful.

EE3 - The use of SNS to publish content about my tourism experiences is easy for me.

EE4 - The use of SNS to publish content about my tourism experiences implies little effort for me.

\section{Social influence}

SI1 - People who are important to me agree that I use SNS to publish content about my tourism experiences. 
SI2 - People who influence my behavior approve that I use SNS to publish content about my tourism experiences.

SI3 - People whose opinions I value think that I should use SNS to publish content about my tourism experiences.

\section{Facilitating conditions}

FC1 - I have the resources necessary to use SNS to publish content about my tourism experiences.

FC2 - I have the knowledge necessary to use SNS to publish content about my tourism experiences.

FC3 - I feel comfortable using SNS to publish content about my tourism experiences.

FC4 - I have no problems using SNS to publish content about my tourism experiences.

\section{Hedonic motivation}

HM1 - Using SNS to publish content about my tourism experiences is fun.

HM2 - Using SNS to publish content about my tourism experiences is enjoyable.

HM3 - Using SNS to publish content about my tourism experiences is very entertaining.

\section{Habit}

HT1 - The use of SNS to publish content about my tourism experiences has become a habit for me.

HT2 - I am addicted to using SNS to publish content about my tourism experiences. 
HT3 - The use of SNS to publish content about my tourism experiences is something that I do on a daily basis.

\section{Privacy concerns}

PC1 - The use of SNS to publish content about my tourism experiences implies a threat to my privacy.

PC2 - The use of SNS to publish content about my tourism experiences may be risky in terms of privacy.

PC3 - The use of SNS to publish content about my tourism experiences can lead to unexpected problems of privacy. 
Appendix B. Descriptive statistics of the variables

\begin{tabular}{|l|c|c|c|c|}
\hline Variable & Mean & Std. Dev. & Skewness & Kurtosis \\
\hline BI1 & 4.74 & 1.85 & -0.52 & -0.75 \\
\hline BI2 & 4.71 & 1.91 & -0.50 & -0.86 \\
\hline BI3 & 4.61 & 2.03 & -0.48 & -1.02 \\
\hline PE1 & 5.06 & 1.73 & -0.74 & -0.28 \\
\hline PE2 & 5.17 & 1.67 & -0.85 & 0.02 \\
\hline PE3 & 5.08 & 1.73 & -0.82 & -0.20 \\
\hline PE4 & 4.96 & 1.78 & -0.69 & -0.44 \\
\hline EE1 & 5.36 & 1.74 & -0.99 & 0.04 \\
\hline EE2 & 5.17 & 1.82 & -0.86 & -0.33 \\
\hline EE3 & 5.26 & 1.79 & -0.93 & -0.18 \\
\hline EE4 & 5.23 & 1.81 & -0.93 & -0.21 \\
\hline SI1 & 4.99 & 1.57 & -0.75 & 0.20 \\
\hline SI2 & 4.94 & 1.58 & -0.70 & 0.07 \\
\hline SI3 & 4.92 & 1.53 & -0.61 & -0.01 \\
\hline FC1 & 5.71 & 1.49 & -1.16 & 0.78 \\
\hline FC2 & 5.54 & 1.63 & -1.13 & 0.54 \\
\hline FC3 & 5.61 & 1.51 & -1.15 & 0.72 \\
\hline FC4 & 5.47 & 1.67 & -1.15 & 0.50 \\
\hline HM1 & 4.84 & 1.74 & -0.67 & -0.39 \\
\hline HM2 & 4.70 & 1.83 & -0.58 & -0.61 \\
\hline HM3 & 4.73 & 1.78 & -0.56 & -0.57 \\
\hline HT1 & 4.17 & 1.94 & -0.18 & -1.17 \\
\hline HT2 & 3.72 & 1.99 & 0.06 & -1.25 \\
\hline HT3 & 3.94 & 1.94 & -0.04 & -1.19 \\
\hline PC1 & 4.07 & 1.80 & -0.14 & -0.96 \\
\hline PC2 & 4.01 & 1.80 & -0.02 & -0.97 \\
\hline PC3 & 3.88 & 1.88 & 0.11 & -1.09 \\
\hline & & & & \\
\hline & & & & -19 \\
\hline
\end{tabular}

